\title{
TINGKAT KEPUASAN PASIEN PESERTA JAMINAN KESEHATAN NASIONAL (JKN) RAWAT JALAN TERHADAP KUALITAS PELAYANAN OBAT DI INSTALASI FARMASI RUMAH SAKIT SILOAM MANADO
}

\author{
Elmi Nurmata Sari ${ }^{1)}$, Gayatri Citraningtyas ${ }^{1)}$, Imam Jayanto ${ }^{1)}$ \\ ${ }^{1)}$ Program Studi Farmasi FMIPA UNSRAT Manado, 95115
}

\begin{abstract}
The quality of health services is a service that can lead to satisfaction in each patient where the procedure is carried out in accordance with the standards and code of ethics that have been set. This study aims to determine the level of satisfaction of JKN participants in outpatient care on the quality of drug service in the Pharmacy Installation of Siloam Hospital, Manado based on five dimensions of service quality namely tangibles, empathy, reliability, responsiveness, and assurance. This research is a descriptive study with prospective data collection. The number of samples is 100 people. Primary data collection was conducted using questionnaires to test the validity and reliability of the questionnaire using the SPSS program. The results obtained by the overall satisfaction index value of -0,010. Satisfaction index in each dimension respectively, among others: tangible-0,14; empathy -0,013; reliability -0,16; responsiveness 0,17; dan0,045 assurance. The conclusion shows that the satisfaction index is negative, which means that outpatient JKN patients are not satisfied with the services provided at the Pharmacy Installation of Siloam Hospital Manado.
\end{abstract}

Keywords: Patient Satisfaction, Quality of Service, Outpatient Care, Siloam Hospital, Manado.

\begin{abstract}
ABSTRAK
Kualitas pelayanan kesehatan adalah pelayanan yang dapat menimbulkan kepuasan pada setiap pasien dimana tata cara penyelenggarannya sesuai dengan standar dan kode etik yang telah ditetapkan. Penelitian ini bertujuan untuk mengetahui tingkat kepuasan pasien peserta JKN rawat jalan terhadap kualitas pelayanan obat di Instalasi Farmasi Rumah Sakit Siloam Manado berdasarkan lima dimensi kualitas pelayanan yakni tangibles, emphaty, reliability, responsiveness, dan assurance. Penelitian ini merupakan penelitian deskriptif dengan pengambilan data secara prospektif. Jumlah sampel sebanyak 100 orang. Pengumpulan data primer dilakukan menggunakan kuisioner uji validitas dan reliabilitas kuisioner menggunakan program SPSS. Hasil penelitian diperoleh nilai indeks kepuasan secara keseluruhan sebesar -0,010. Indeks kepuasan pada setiap dimensi berturut-turut antara lain: tangible $-0,14$; emphaty $-0,013$; reliability $-0,16$; responsiveness 0,17 ; dan assurance 0,045 . Kesimpulannya menunjukkan indeks kepuasan bernilai negatif yang berarti pasien peserta JKN rawat jalan belum merasa puas terhadap pelayanan yang diberikan di Instalasi Farmasi Rumah Sakit Siloam Manado.
\end{abstract}

Kata Kunci: Kepuasan Pasien, kualitas Pelayanan, Rawat Jalan, Rumah Sakit Siloam Manado. 


\section{PENDAHULUAN}

Kualitas pelayanan kesehatan adalah pelayanan kesehatan yang dapat menimbulkan kepuasan pada setiap pasien dimana tata cara penyelenggaraannya sesuai dengan standar dan kode etik yang telah ditetapkan. Kepuasan menjadi bagian penting dalam pelayanan kesehatan sebab kepuasan pasien tidak dapat dipisahkan dari kualitas pelayanan kesehatan. Pasien merasa puas apabila kinerja layanan kesehatan yang diperolehnya sama atau melebihi harapannya dan sebaliknya, ketidakpuasan atau perasaan kecewa pasien akan muncul apabila kinerja layanan kesehatan yang diperolehnya itu tidak sesuai dengan harapannya (Daulay, 2015).

Suatu pelayanan dikatakan berkualitas oleh pasien ditentukan oleh kenyataan apakah jasa yang diberikan memenuhi kebutuhan pasien dan pelayanan yang diterima oleh pasien memuaskan atau mengecewakan. Kepuasan dinilai pertama kali dari pasien masuk rumah sakit sampai pasien keluar dari rumah sakit. Kenyataan menunjukkan bahwa pasien yang tidak puas akan memberikan rekomendasi kepada pasien lainnya, sehingga mempengaruhi sikap dan keyakinan orang lain untuk tidak berkunjung ke sarana tersebut (Tjiptono dkk, 2001).

Penelitian sebelumnya oleh Aryani (2015) dengan judul "Analisa Kepuasan Pasien Rawat Jalan Terhadap Kualitas Pelayanan Kefarmasian di Rumah Sakit Islam Ibnu Sina Pekanbaru" bahwa pelayanan di Instalasi Farmasi yang dirasakan pasien rawat jalan belum merasa puas terhadap pelayanan yang diberikan oleh petugas Instalasi Farmasi dari penelitian terdapat waktu tunggu pasien yang terlalu lama, proses antrian yang tidak jelas dan pasien merasa seharusnya dilayani terlebih dahulu tetapi tidak dilayani terlebih dahulu pada waktu jam-jam ramai di instalasi farmasi dikarenakan tidak tersediannya obat yang diminta sehingga mengakibatkan kekecewaan bagi pasien.

Berdasarkan hasil wawancara yang dilakukan di Instalasi Farmasi Rumah Sakit Siloam Manado, belum pernah dilakukan penelitian terhadap tingkat kepuasan pasien terhadap kualitas pelayanan obat di Instalasi Farmasi Rumah Sakit Siloam Manado. Hal ini peneliti tertarik melakukan penelitian ini.

\section{METODOLOGI PENELITIAN}

Penelitian ini merupakan jenis penelitian deskriptif dengan pengambilan sampel secara prospektif. Penelitian ini dilaksanakan di Rumah Sakit Siloam Manado. Pengambilan data dilakukan pada bulan April - Mei 2019. Populasi pada penelitian ini adalah seluruh pasien peserta JKN rawat jalan maupun pengantarnya yang mengambil obat di Instalasi Farmasi Rumah Sakit Siloam Manado. Sedangkan untuk sampel dalam penelitian ini ditetapkan dengan menggunakan metode nonprobability sampling tipe anccidental sampling, yaitu teknik pengambilan sampel secara bebas, dimana peneliti dapat mengambil orang yang ditemui sebagai sampel penelitian, dengan catatan orang tersebut memenuhi criteria sampel penelitian.

Besarnya sampel berdasarkan rumus Slovin (Sani, 2016).

$$
n=\frac{\mathrm{N}}{1+\mathrm{N}(e)^{2}}
$$

Keterangan:

$$
n \text { : Besar sampel }
$$

$\mathrm{N}$ : Populasi yang diketahui

e : Nilai standar eror $10 \%=(0,1)$.

diketahui bahwa besar populasi penelitian adalah 6500 orang, maka jumlah 
minimal sampel penelitian adalah 100 orang. Jenis data yang digunakan adalah data primer yakni wawancara dan kuisioner. Metode yang digunakan adalah uji validitas untuk menunjukkan sejauh mana ketepatan dan kecermatan suatu alat ukur dalam melakukan fungsi pengukurannya dan uji reliabilitas suatu alat ukur dapat dipercaya, dalam menganalisis data menggunakan rumus sebagai berikut:

$$
x=\frac{\sum x i}{n} \quad y=\frac{\sum y i}{n}
$$

Keterangan:

$x=$ Skor rata-rata kenyataan/kinerja

$y=$ Skor rata-rata harapan

$n=$ Jumlah responden

$\sum x i=$ Jumlah skor item pernyataan kenyataan

$\sum y i=$ Jumlah skor item pernyataan harapan.

Analisis yang digunakan untuk menghitung total kualitas pelayanan di Instalasi Farmasi pada penelitian ini menggunakan model Weighted Servqual sebagai berikut (Priyatno, 2010):

$$
I k j=\sum_{I=0}^{n}(P i j-E i j)
$$

Keterangan:

$I k j=$ Indeks total kualitas pelayanan

$P i j=$ Performance I pada objek $\mathbf{J}$

$E i j=$ Expectance (harapan atribut pada objek j)

$n$ = Jumlah pernyataan.

Berdasarkan hasil indeks total kualitas pelayanan dapat diartikan bahwa :

1 .indeks nol

Kondisi yang menyatakan harapan pelanggan tepat sama dengan kinerja yang dihasilkan oleh perusahaan.

\section{Indeks negatif}

Kondisi yang menyatakan harapan pelanggan lebih besar dari kinerja aktual yang dihasilkan perusahaan, keadaan ini menyebabkan kualitas pelayanan menjadi tidak sesuai dengan harapan pelanggan.

3. Indeks positif

Kondisi yang menyatakan harapan pelanggan mengenai pelayanan lebih kecil dari kinerja yang diberikan dan dampaknya adalah kualitas pelayanan yang ideal menurut pelanggan.

\section{HASIL DAN PEMBAHASAN}

Karakteristik Pasien JKN Rawat Jalan

Di Instalasi Farmasi Rumah Sakit Siloam Manado.

Tabel 1. Karakteristik Pasien JKN Rawat Jalan Di Instalasi Farmasi

\begin{tabular}{|c|c|c|}
\hline \multirow{2}{*}{ Karateristik } & \multicolumn{2}{|c|}{ Total } \\
\hline & $\mathbf{N}$ & $(\%)$ \\
\hline \multicolumn{3}{|l|}{ Jenis Kelamin } \\
\hline Laki-laki & 52 & $52 \%$ \\
\hline Perempuan & 48 & $48 \%$ \\
\hline \multicolumn{3}{|l|}{ Usia(Depkes, 2009) } \\
\hline (17 - 24 tahun) & 13 & $13 \%$ \\
\hline (25 - 44 tahun) & 68 & $68 \%$ \\
\hline (45 - 54 tahun) & 14 & $14 \%$ \\
\hline (55- 64 tahun $)$ & 5 & $5 \%$ \\
\hline (>65 tahun) & 0 & $0 \%$ \\
\hline \multicolumn{3}{|l|}{ Pendidikan } \\
\hline \multicolumn{3}{|l|}{ Terakhir } \\
\hline Tidak Sekolah & 0 & $0 \%$ \\
\hline SD/Sederajat & 0 & $0 \%$ \\
\hline SMP/Sederajat & 6 & $6 \%$ \\
\hline SMA/Sederajat & 32 & $32 \%$ \\
\hline Perguruan & 62 & $62 \%$ \\
\hline Tinggi & & \\
\hline \multicolumn{3}{|l|}{ Jenis Pekerjaan } \\
\hline $\begin{array}{l}\text { Pegawai Negeri } \\
\text { Sipil }\end{array}$ & 30 & $30 \%$ \\
\hline TNI & 1 & $1 \%$ \\
\hline POLRI & 4 & $4 \%$ \\
\hline Swasta & 18 & $18 \%$ \\
\hline Petani & 2 & $2 \%$ \\
\hline Nelayan & 0 & $0 \%$ \\
\hline Wirausaha & 4 & $4 \%$ \\
\hline Dan Lain-lain & 41 & $41 \%$ \\
\hline
\end{tabular}
Rumah Sakit Siloam Manado. 
Hasil penelitian menunjukkan responden terbanyak (52\%) berjenis kelamin laki-laki yakni 52 pasien. Berdasarkan penelitian yang dilakukan di instalasi farmasi rumah sakit siloam manado, responden yang memberikan masukan dalam mengisi kuesioner bukan hanya pasien JKN yang sedang melakukan pengobatan rawat jalan tetapi juga keluarga/kerabat yang mengantar pasien sehingga pengaruh untuk jenis kelamin pada dasarnya tidak berpengaruh terhadap perbedaan untuk menilai kepuasan pasien.

Karakteristik usia pasien pada penelitian ini menunjukkan pasien JKN rawat jalan yang menerima pelayanan obat di Instalasi Farmasi Rumah Sakit Siloam Manado pada kelompok usia 25-44 tahun sebanyak 68 pasien (68\%) (Tabel 1 ).

Hasil Penelitian menunjukan banyak ditemukan pekerjaan diluar dari pilihan seperti ibu rumah tangga, honorer, supir, mahasiswa, dan lain-lain 41 pasien (41\%). Demikian pula dengan penelitian yang dilakukan Laeliyah (2015), dari 92 responden sebanyak 35 pasien $(38,0 \%)$ dengan jenis pekerjaan di luar dari pilihan seperti ibu rumah tangga, supir, petani, dan lain-lain. Penelitian ini menunjukkan bahwa pekerjaan mempengaruhi komunitas dimana mereka bergaul sehingga mereka yang tidak bekerja atau memiliki pendidikan rendah dan lebih mempertahankan nilai-nilai tradisional.

Karakteristik pasien berdasarkan pendidikan terakhir menunjukan bahwa yang paling banyak ditemukan pasien pada status pendidikan terakhir perguruan tinggi sebanyak 62 pasien $(62 \%)$ pasien dengan status pendidikan perguruan tinggi lebih membandingkan pengobatan pada setiap instalasi farmasi.

\section{Analisis Tingkat Kepuasan Pada Pasien JKN Rawat Jalan Terhadap Kualitas Pelayanan Obat di Instalasi Farmasi Rumah Sakit Siloam Secara Keseluruhan.}

Tabel 2. Perhitungan Dan Penilaian Tingkat Kepuasan Pasien JKN Rawat Jalan Pada Setiap Item.

\begin{tabular}{lllllllll}
\hline Dimensi & Item & Harapan & Kenyataan & $\begin{array}{l}\text { Rerata } \\
\text { Harapan }\end{array}$ & $\begin{array}{l}\text { Rerata } \\
\text { Kenyataan }\end{array}$ & Ikj & $\begin{array}{l}\text { Rerata } \\
\text { Per } \\
\text { dimensi }\end{array}$ & $\begin{array}{l}\text { Pering } \\
\text {-kat }\end{array}$ \\
\hline Tangibles & 1 & 368 & 369 & 3,68 & 3,69 & 0,01 & $-0,14$ & 3 \\
& 2 & 359 & 389 & 3,59 & 3,89 & 0,3 & & \\
& 3 & 364 & 389 & 3,64 & 3,89 & 0,25 & & \\
& 4 & 364 & 380 & 3,64 & 3,80 & 0,16 & & \\
& 5 & 348 & 341 & 3,48 & 3,41 & $-0,07$ & & \\
& 6 & 355 & 359 & 3,55 & 3,59 & 0,04 & & \\
& 7 & 361 & 174 & 3,61 & 1,74 & $-1,87$ & & \\
& 8 & 351 & 359 & 3,51 & 3,59 & 0,08 & & \\
\hline Emphaty & 9 & 349 & 357 & 3,49 & 3,57 & 0,08 & $-0,013$ & 5 \\
& 10 & 359 & 349 & 3,59 & 3,49 & $-0,1$ & & \\
& 11 & 361 & 365 & 3,61 & 3,65 & 0,04 & & \\
& 12 & 358 & 351 & 3,58 & 3,51 & $-0,07$ & & \\
& 13 & 353 & 373 & 3,53 & 3,73 & 0,2 & 0,16 & 2
\end{tabular}




\begin{tabular}{lllllllll} 
Reliability & 14 & 357 & 369 & 3,57 & 3,69 & 0,12 & & \\
& 15 & 360 & 374 & 3,60 & 3,74 & 0,14 & & \\
\hline Respon- & 16 & 355 & 374 & 3,55 & 3,74 & 0,19 & 0,17 & 1 \\
siveness & 17 & 359 & 374 & 3,59 & 3,74 & 0,15 & & \\
\hline Assurance & 18 & 363 & 379 & 3,63 & 3,79 & 0,16 & 0,045 & \\
& 19 & 349 & 324 & 3,49 & 3,24 & $-0,25$ & & 4 \\
& 20 & 368 & 386 & 3,68 & 3,86 & 0,18 & & \\
& 21 & 363 & 372 & 3,63 & 3,72 & 0,09 & & \\
\hline \multicolumn{7}{l}{ Nilai Kepuasan Secara Keseluruhan } \\
\hline
\end{tabular}

Gambaran Kepuasan Pasien JKN Rawat Jalan Terhadap Pelayanan Obat di Instalasi Farmasi Rumah Sakit Siloam Manado.

\section{a. Gambaran Kepuasan Pasien JKN Rawat Jalan Berdasarkan Dimensi Tangibles}

Kuesioner pada dimensi tangibles diwakili oleh delapan butir pernyataan diantaranya lokasi Instalasi Farmasi Rumah Sakit Siloam Manado mudah dijangkau, Instalasi Farmasi sudah tersedia obat yang

lengkap sesuai resep, memiliki toilet/WC yang bersih, memiliki ruang tunggu yang nyaman, dilengkapi dengan nomor antrian instalasi terlihat bersih dan rapi, memiliki tempat parkir yang aman dan luas, petugas instalasi berpakaian yang bersih dan rapi.

Kepuasan pasien JKN rawat jalan dari dimensi tangibles terhadap kualitas pelayanan di Instalasi Farmasi Rumah Sakit Siloam Manado dari nilai indeks total kualitas pelayanan pada Tabel 2, secara keseluruhan kurang memuaskan pasien, hal ini menandakan belum terpenuhinya harapan konsumen terhadap fasilitas yang ada di Instalasi Farmasi Rumah Sakit Siloam Manado terlihat pada Tabel 2, nilai Ikj terendah $(-1,87)$ ketersediaan tempat parkir yang aman dan luas, nilai Ikj tertinggi terdapat 2 item dengan nilai $(0,3$ dan 0,25$)$
Instalasi Farmasi tersedia obat yang lengkap sesuai resep dan memiliki toilet/WC yang bersih. Secara keseluruhan pasien merasa belum puas dengan dimensi berwujud (tangibles) yang diberikan rumah sakit ini terlihat dengan nilai Ikj yang menunjukkan nilai negatif dengan nilai rerata dimensi yaitu $-0,14$.

\section{b. Gambaran Kepuasan Pasien JKN Rawat Jalan Berdasarkan Dimensi Emphaty}

Kuesioner pada dimensi emphaty diwakili oleh empat pernyataan diantaranya tentang ramah dan sopan santun, memiliki sikap peduli saat memberikan pelayanan obat, mudah diajak berkomunikasi, perhatian tanpa memandang pasien dengan status sosial di Instalasi Farmasi Rumah Sakit Siloam Manado pada saat memberikan pelayanan obat kepada pasien.

Berdasarkan Tabel 2 dapat diketahui nilai Ikj terendah pada dimensi ini terdapat pada pernyataan $(-0,1)$ petugas Instalasi Farmasi Rumah Sakit Siloam Manado memiliki sikap peduli pada saat memberikan pelayanan obat dan nilai Ikj tertinggi $(0,04)$ dengan pernyataan petugas di Instalasi Farmasi Rumah Sakit Siloam Manado mudah diajak berkomunikasi dalam hal penjelasan terkait obat ke pasien. Secara keseluruhan pasien merasa belum puas dengan dimensi empati yang diberikan rumah sakit, ini terlihat dengan nilai Ikj yang menunjukkan nilai negatif dengan nilai rerata per dimensi 
yaitu -0,013 meskipun begitu nilai Ikj dimensi ini merupakan nilai tertinggi dibandingkan dngan nilai $\mathrm{Ikj}$ dimensi lainnya. Namun berdasarkan harapan yang diinginkan pasien, nilai tersebut masih menunjukkan ketidakpuasan pasien.

Sebagaimana dengan penelitian Isnandar, dkk (2013), yang mendapatkan nilai indeks total kepuasan pasien pada dimensi ini berada pada nilai negatif, menyatakan perlunya pelatihan dalam hal keterampilan antar pribadi/petugas khususnya menyangkut interaksi dengan pasien dan mengembangkan metode rekrutmen dan referensi inovatif untuk menarik karyawan terbaik, maka secara tidak langsung pasien akan menjadi antusias dan patuh dalam menjalankan terapi pasien dalam meminum obat.

\section{c. Gambaran Kepuasan Pasien JKN Rawat Jalan Berdasarkan Dimensi Reliability}

Dimensi reliability (keandalan)

berkaitan dengan kemampuan untuk memberikan kualitas pelayanan kepada pasien secara akurat dan memuaskan. Kuesioner pada dimensi reliability diwakili oleh tiga butir pernyataan diantaranya tentang prosedur pelayanan Instalasi Farmasi Rumah Sakit Siloam Manado yang tidak berbelit-belit, keperluan pasien yang ditangani dengan cepat dan tepat, dan petugas yang selalu siap menangani setiap keluhan dari pasien terhadap pelayanan obat.

Berdasarkan Tabel 2 dapat diketahui nilai Ikj terendah berada pada pernyataan $(0,12)$ pasien masih merasa belum puas terhadap kecepatan dan ketepatan pelayanan obat yang diberikan petugas Instalasi Farmasi kepada pasien disebabkan banyaknya pasien sehingga petugas instalasi kurang tepat terhadap pelayanan obat pada pasien dan nilai Ikj tertinggi $(0,14)$ petugas di Instalasi
Farmasi selalu siap menangani setiap keluhan dari pasien terhadap pelayanan obat. Berdasarkan Tabel 2, nilai Ikj secara keseluruhan pada dimensi ini menunjukkan angka positif yaitu 0,16 artinya kenyataan yang diterima pasien sudah memuaskan/ideal seperti yang diharapkan oleh pasien dan pasien tidak merasa prosedur dalam pelayanan di Instalasi Farmasi berbelit-belit.

\section{d. Gambaran Kepuasan Pasien JKN Rawat Jalan Berdasarkan Dimensi Responsiveness}

Dimensi responsiveness berkaitan dengan kemampuan dari petugas dalam hal merespon permintaan pasien terhadap keluhan maupun memberikan informasi mengenai pelayanan yang diberikan. Kuesioner pada dimensi responsiveness ini diwakili oleh dua butir pernyataan diantaranya tentang memberikan informasi obat secara jelas dan mudah dimengerti kepada pasien tentang obat/resep yang ditebus dan kesiapan petugas dalam menangani setiap keluhan pasien.

Berdasarkan Tabel 2, dapat diketahui nilai Ikj dari 2 item tersebut mempunyai nilai yang sama yaitu $(0,19$ dan 0,15$)$ dengan pernyataan pasien mendapatkan informasi yang jelas dan mudah dimengerti tentang resep/obat yang ditebus dan petugas Instalasi Farmasi selalu siap dalam menangani setiap keluhan dari pasien. Secara keseluruhan pasien sudah merasa puas dengan dimensi ketanggapan yang diberikan rumah sakit, ini terlihat dengan nilai Ikj yang menunjukkan nilai positif dengan nilai rerata dimensi yaitu 0,17. Dari nilai indeks total kualitas pelayanan (Ikj) item pada variable ketanggapan masing-masing mendapatkan nilai positif, artinya secara keseluruhan pasien sudah puas terhadap pelayanan yang diberikan petugas pada dimensi ini. 


\section{e. Gambaran Kepuasan Pasien JKN Rawat Jalan Berdasarkan Dimensi Assurance}

Dimensi Assurance (jaminan) merupakan tolak ukur kemampuan serta pengetahuan petugas agar sepenuhnya dapat dipercaya tanpa ragu sebagai profesionalisme yang handal. Selisih antara kenyataan dan harapan item pada dimensi jaminan, nilai Ikj terendah $(-0,25)$ petugas Instalasi Farmasi memberikan konseling kepada pasien dan nilai Ikj tertinggi $(0,18)$ obat yang dibeli terjamin kualitasnya.

Pasien belum merasa puas pada dimensi ini karena sebagian besar pasien merasa belum pernah menerima pelayanan informasi obat mengenai efek samping obat atau konseling dari petugas di Instalasi Farmasi, ini terlihat pada nilai signifikan dari pernyataan tentang informasi efek samping obat dan pemberian konseling oleh petugas di Instalasi Farmasi. Sejalan dengan penelitian Isnindar., dkk (2013), yang dilakukan di Instalasi Farmasi RSUD Dr. Soedarso Pontianak tentang kepuasan pasien didapatkan bahwa pada dimensi jaminan pasien merasa tidak pernah melakukan konseling di Instalasi Farmasi ataupun menerima pelayanan informasi obat, padahal ruang konsultasi sudah tersedia pada instalasi tersebut.

\section{KESIMPULAN}

Pasien peserta JKN rawat jalan belum merasa puas terhadap pelayanan yang diberikan oleh Instalasi Farmasi Rumah Sakit Siloam Manado. Hal ini di lihat dari nilai kepuasan Ikj pasien sebesar -0,010, dimana nilai yang diperoleh dari rerata nilai indeks total kualitas pelayanan (Ikj) antara harapan dan kenyataan setiap item pernyataan dari dimensi tangibles, dimensi emphaty, dimensi reliability, dimensi responsiveness, dan dimensi assurance.

\section{SARAN}

Bagi pihak Rumah Sakit Siloam memperbaiki kinerja pelayanan kesehatan terutama pada dimensi emphaty dengan item petugas Instalasi Farmasi Rumah Sakit Siloam Manado memiliki sikap peduli pada saat memberikan pelayanan obat dan tangibles pada item tempat parkir yang aman dan luas.

\section{DAFTAR PUSTAKA}

Aryani, F. 2015.Analisa Kepuasan Pasien Rawat Jalan Terhadap Kualitas Pelayanan Di Instalasi Farmasi Rumah Sakit Islam Ibnu Sina Pekanbaru. Sekolah Tinggi Farmasi Riau. Jurnal Pharmacy, 12:(1);109110

Arikunto, S. 2006. Prosedur Penelitian Suatu Pendekatan Praktik.Jakarta, PT Rineka Cipta.

Daulay, M.A. 2015. Tingkat Kepuasan Pasien Rawat Jalan Peserta BPJS Kesehatan Terhadap Pelayanan Kefarmasian Di Dua Puskesmas Di Kota Medan,[Skripsi], Fakultas Farmasi, Universitas Sumatera Utara, Medan.

Herjunianto,H., Dian,Y., Umar,E. 2014. Faktor Yang Mempengaruhi Cakupan Layanan Farmasi Di Instalasi Rawat Jalan Rumah Sakit.Jurnal Kedokteran Brawijaya. 28:(1);8-13.

Isnindar,M., Wahyono, A., Budi, S. 2013. Tingkat Kepuasan Pasien Rawat Inap Di Ruangan Penyakit Dalam 
PHARMACON- PROGRAM STUDI FARMASI, FMIPA, UNIVERSITAS SAM RATULANGI,

Terhadap Pelayanan Di Instalasi

Farmasi Rumah Sakit Periode

Desember 2011-Februari

2012.Program Studi Farmasi.

Universitas Tanjungpura

Pontianak.Jurnal Manajemen dan

Pelayanan Farmasi.Vol 3 No 4.231248.

Laeliyah, N. 2015. Waktu tunggu pelayanan rawat jalan dengan kepuasan pasien terhadap pelayanan di Rawat Jalan RSUD Kabupaten Indramayu. Program Diploma III Rekam Medis Fakultas Sekolah Vokalis Universitas Gadjah Mada. Fakultas Kedokteran Universitas Gadjah Mada.Jurnal Kesehatan Vokasional.1(2): 102-112.

Priyatno, D. 2010. Paham Analisa Statistik Data Dengan SPSS. Yogyakarta: Madiakom. Hal: 90, 97-98.

Supranto. 2006. Pengukuran Tingkat Kepuasan Konsumen. Jakarta, Rinekacipta.

Sani, F. 2016. Metodologi Penelitian Farmasi Komunitas dan Eksperimental Edisi 1 Cetak 1. Yogyakarta: Deepublish. 